\title{
PERBEDAAN EFEKTIVITAS DISKUSI KELOMPOK, MOTIVASI INTRINSIK DAN NILAI MODUL DARI MAHASISWA YANG DIFASILITASI DOSEN DAN TUTOR SEBAYA
}

\author{
I Made Pariartha*, Rossi Sanusi**, Tridjoko Hadianto** \\ * Fakultas Kedokteran Universitas Warmadewa, Denpasar, Bali \\ ** Fakultas Kedokteran Universitas Gadjah Mada, Yogyakarta
}

\begin{abstract}
Background: Peer teaching is a teaching method that widely applied in many medical institutions. This research was designed to evaluate group discussion effectiveness, intrinsic motivation, and student achievement differences between peer tutor-facilitated students and faculty tutor-facilitated students.

Method: This research is an experimental research using post"test only control group design during the implementation of third and fourth module of the Cardiovascular Block (consist of five modules). Fifty-nine third year students were randomly assigned into two groups. Three experimental groups $(n=30)$ was facilitated by peer tutors (PT) and three control groups $(n=29)$ was facilitated by faculty tutors (FT). Two students were randomly elected from each PT group as peer tutor. A six hour training was given to the peer tutors. In the end of the third and fourth module, group discussion effectiveness, intrinsic motivation, and student achievement in those modules were evaluated using Tutorial Group Effectivenes Instrument (TGEI) questionnaire, Intrinsic Motivation Inventory (IMI) questionnaire, and 20 multiple choice questions, respectively. Mean differences between groups were measured by Cohen's $d$ with the practical significance at Cohen's $d>1$.

Results: There was no significant differences of group discussion effectiveness (Cohen's $d=-0.41$ ) and intrinsic motivation (Cohen's $d=-0.83$ ) between two groups. Significant difference in student achievement is found between those groups, peer tutor"facilitated students score higher than faculty tutor"facilitated students (Cohen's $d=2.96$ ). Peer tutors showed higher achievement than discussants (Cohen's $d=1.86$ ).

Conclusion: The results showed that peer tutor can facilitated group discussion as well as faculty tutor in group discussion effectiveness, intrinsic motivation and student achievement paramaters. There was advantage for students who given role as peer tutor.
\end{abstract}

KEYWORDS: peer teaching, group discussion, intrinsic motivation, group effectiveness, student achievement

\section{ABSTRAK}

Latar belakang: Pengajaran oleh teman sebaya (peer teaching) merupakan salah satu metode pengajaran yang secara luas diterapkan di banyak institusi kedokteran. Penelitian ini dirancang untuk menilai perbedaan efektivitas diskusi kelompok, motivasi intrinsik dan nilai modul dari mahasiswa yang difasilitasi tutor sebaya dan mahasiswa yang difasilitasi tutor dosen.

Metode: Penelitian ini merupakan penelitian eksperimental dengan post-test only control group. Penelitian ini dilakukan pada modul 3 dan 4 Blok Kardiovaskular. Lima puluh sembilan mahasiswa tahun ketiga secara acak ditempatkan ke dalam dua kelompok. Tiga kelompok $(\mathrm{n}=30)$ difasilitasi oleh tutor sebaya (TS) dan tiga kelompok $(\mathrm{n}=29)$ difasilitasi oleh tutor dosen (TD). Dua mahasiswa diambil secara acak dari masing-masing kelompok TS sebagai tutor sebaya. Tutor sebaya mendapatkan pelatihan selama enam jam. Pada akhir modul 3 dan 4, efektivitas diskusi kelompok dinilai dengan kuesioner Tutorial Group Effectivenes Instrument (TGEI), motivasi intrinsik dinilai dengan kuesioner Intrinsic Motivation Inventory (IMI) dan nilai modul dinilai dengan 20 soal pilihan berganda. Beda rerata dinilai dengan Cohen's $d$ dengan batas kemaknaan praktis Cohen's $d>1$.

Korespondensi: med.pariartha@gmail.com 
Hasil: Antara mahasiswa yang difasilitasi tutor sebaya dengan mahasiswa yang difasilitasi tutor dosen, tidak terdapat perbedaan yang bermakna secara praktis pada efektivitas diskusi kelompok (Cohen's $d=-0.41$ ) dan motivasi intrinsik (Cohen's $d=-0.83$ ). Perbedaan yang bermakna secara praktis terdapat pada nilai modul, mahasiswa yang difasilitasi tutor sebaya mempunyai nilai yang lebih tinggi dibandingkan mahasiswa yang difasilitasi tutor dosen (Cohen's $d=2.96$ ). Tutor sebaya mempunyai nilai modul yang lebih tinggi dibandingkan dengan peserta diskusi (Cohen's $d=1.86$ ).

Kesimpulan: Tutor sebaya dapat memfasilitasi diskusi kelompok sama baiknya dengan tutor dosen pada parameter keefektifan diskusi kelompok, motivasi intrinsik dan nilai modul. Terdapat keuntungan bagi mahasiswa yang diberikan peran sebagai tutor sebaya.

KATA KUNCI: peer teaching, diskusi kelompok, motivasi intrinsik, efektivitas diskusi, nilai modul

\section{PENDAHULUAN}

Fakultas Kedokteran Universitas Warmadewa (FK Unwar) menerapkan strategi pembelajaran SPICES (Student-centered, Problem-based, Integrated, Community-based, Early clinical exposure dan Systematic). Pemilihan strategi tersebut membutuhan jumlah dosen yang banyak, sedangkan FK Unwar masih menghadapi permasalahan keterbatasan dosen. Salah satu strategi untuk mengatasi permasalahan tersebut adalah dengan menerapkan strategi pembelajaran oleh teman sebaya (peer teaching).

Pengajaran oleh teman sebaya (peer teaching) merupakan strategi pembelajaran yang menarik dan telah banyak diterapkan dan diteliti dalam pendidikan kedokteran. Alasan rasional untuk menjadikan mahasiswa sebagai pengajar (tutor) berlandaskan pada dua theoretical behavior constructs, yaitu role theory (teori peran) yang dideskripsikan oleh Allen tahun 1976 dan cognitive cogruence theory (teori keselarasan kognitif) yang dipublikasikan oleh Cornwall tahun $1979 .{ }^{1}$

Teori peran menyatakan bahwa dosen dan mahasiswa mempunyai peran stereotipe yang berbeda dalam pada harapan-harapan, tanggung jawab dan status.

Secara teori, keselarasan peran antara tutor sebaya dan mahasiswa akan mempunyai pengaruh yang menguntungkan pada motivasi oleh karena keaktifan dan antusiasme dari tutor sebaya. Teori keselarasan kognitif menyatakan bahwa struktur kognitif seorang ahli berbeda dengan pemula (novice). Pernyataan tersebut menunjukkan bahwa terdapat ketidakselarasan kognitif antara dosen dan mahasiswa, namun terdapat keselarasan kognitif antara tutor sebaya dengan mahasiswa. ${ }^{1}$
Mahasiswa yang mendapatkan tugas sebagai pengajar juga merupakan salah satu cara untuk meningkatkan peran dan tanggung jawab mahasiswa dalam pemelajarannya. Hal tersebut disokong oleh ucapan terkenal dari Socrates yang menyatakan "docendo discimus" yang berarti kita belajar dengan mengajar atau ucapan ahli filsafat Prancis Joseph Joubert yang menyatakan "mengajar adalah belajar dua kali" menunjukkan bahwa mengajar merupakan cara yang efektif untuk belajar. Istilah "dokter" berasal dari bahasa Inggris "doctor" yang dapat mengandung beberapa arti. Arti yang paling umum diterima dari kata dokter adalah penyembuh medis (medical healer). Selain arti sebagai penyembuh, kata "doctor" juga berakar pada bahasa latin "docere" yang artinya mengajar (to teach). Tidak dapat disangkal, salah satu tugas kunci seorang dokter adalah mengajar. Dokter mempunyai kewajiban mengajar pasien tentang diagnosis dan rencana penanganan pasien. ${ }^{2}$

Metode pengajaran oleh teman sebaya banyak memberikan keuntungan yang bisa didapatkan, baik untuk pengajar sebaya, mahasiswa, maupun institusi. ${ }^{4}$ Metode pengajaran oleh teman sebaya telah digunakan secara luas dalam bidang kedokteran. Berbagai alasan telah menjadi pertimbangan dalam menerapkan metode ini. ${ }^{5}$ Asumsi-asumsi tentang teori-teori yang mendasari keuntungan mahasiswa yang diajar dan mahasiswa yang mengajar telah dikemukakan. ${ }^{6}$ Penelitian tentang keefektivitasannya juga telah banyak dilakukan. Memberikan peran mengajar kepada mahasiswa juga diasumsikan meningkatkan motivasi intrinsik mahasiswa untuk terlibat dalam pengajaran sehingga memperkuat pembelajaran mahasiswa. ${ }^{7}$ 
Kegiatan pengajaran oleh teman sebaya juga berladaskan pada teori motivasi, yaitu self-determination theory (SDT). ${ }^{8}$ Kewajiban untuk mengajar dapat dipandang sebagai pendorong (motivator ekstrinsik), namun mengajar juga dapat memperkuat motivasi intrinsik. SDT memprediksi mahasiswa yang berperan sebagai tutor sebaya akan lebih cepat dalam mengembangkan motivasi intrinsik untuk mempelajari materi pengajaran dibandingkan ketika mahasiswa hanya bertindak sebagai mahasiswa biasa. ${ }^{8}$

Metode pengajaran oleh teman sebaya telah secara luas diterapkan dalam pendidikan kedokteran, baik dalam tahap sarjana maupun profesi. Khusus dalam penerapan dalam tahap sarjana, metode ini telah diterapkan dalam pengajaran kognitif maupun keterampilan klinik. Dalam bidang keterampilan klinik, bentuk yang umum adalah mahasiswa yang lebih senior sebagai instruktur keterampilan klinik bagi mahasiswa yang lebih junior. ${ }^{9}$ ${ }^{12}$ Dalam pendidikan akademis tahap sarjana, bentuk pengajaran oleh teman sebaya lebih bervariasi. Bentuk metode ini paling sering diterapkan dalam kegiatan diskusi kelompok kecil, dan yang menjadi tutor adalah mahasiswa. Variasi terjadi pada tingkat akademik mahasiswa yang menjadi tutor diskusi kelompok kecil.

Tingkat akademik mahasiswa yang paling umum dijadikan tutor sebaya adalah mahasiswa dengan tingkat akademik yang lebih tinggi (satu tahun atau lebih). 2,13,14,15 Beberapa studi menggunakan tutor sebaya dalam diskusi kelompok kecil yang berasal dari mahasiswa tahun yang sama (true peer tutoring), yang biasanya diacak dari kelompok mahasiswa. ${ }^{16-19}$ Peran yang dilakukan oleh tutor mahasiswa sama seperti dengan peran tutor dosen, yaitu menstimulasi terjadinya elaborasi, mengarahkan proses pembelajaran, menstimulasi integrasi, menstimulasi terjadinya interaksi dan memberikan umpan balik.

Penelitian ini didesain untuk menilai perbedaan efektivitas diskusi kelompok, motivasi intrinsik untuk terlibat dalam kegiatan diskusi kelompok dan nilai modul antara mahasiswa yang difasilitasi tutor sebaya dan mahasiswa yang difasilitasi tutor dosen.

\section{METODE}

Pengumpulan data dilaksanakan dengan menggunakan rancangan eksperimental dengan post-test only control group
Penelitian ini dilaksanakan pada kegiatan diskusi kelompok di Blok Kardiovaskular. Blok Kardiovaskular ini berlangsung selama empat minggu dan terdiri dari lima modul. Pada modul satu dan dua, mahasiswa membahas tentang ilmu-ilmu dasar kardiovaskular (anatomi, fisiologi, dan histologi) sedangkan pada modul tiga, empat, dan lima mahasiswa membahas tentang masalah-masalah klinis yang terkait dengan sistem kardiovaskular. Setiap modul disertai oleh dua kali diskusi kelompok. Waktu untuk satu kali diskusi kelompok adalah 100 menit. Penelitian ini diterapkan pada modul tiga dan empat. Penelitian ini telah disetujui oleh Komite Etik FK UGM dan semua subjek dalam penelitian telah memberikan persetujuan secara tertulis untuk ikut serta dalam penelitian.

Lima puluh sembilan mahasiswa tahun ketiga dibagi menjadi dua kelompok, yaitu tiga kelompok perlakuan (30 mahasiswa) dan tiga kelompok kontrol (29 mahasiswa). Pada modul satu dan dua, diskusi kelompok pada kedua kelompok difasilitasi oleh tutor dosen. Pada modul tiga dan empat, diskusi kelompok pada kelompok perlakuan difasilitasi oleh tutor sebaya, sedangkan diskusi kelompok pada kelompok kontrol difasilitasi oleh tutor dosen. Pada modul lima, diskusi kelompok pada kedua kelompok difasilitasi oleh tutor dosen. Tutor sebaya diambil secara acak dari mahasiswa di setiap kelompok perlakuan dengan kriteria inklusi IPK $\geq 3.00$ dan kriteria eksklusi pernah bermasalah dengan perilaku.

Tutor sebaya mendapatkan pelatihan selama 6 jam yang mencakup materi tentang pembelajaran dalam kelompok kecil, peran ketua, sekretaris, dan anggota dalam diskusi kelompok, peran fasilitator, teknik memfasilitasi diskusi, teknik bertanya, dan memberikan umpan balik yang konstruktif. Pada akhir diskusi kelompok, mahasiswa akan dinilai dalam tiga parameter, yaitu efektivitas diskusi, motivasi intrinsik dan nilai ujian modul dengan alat ukur berturut-turut: Tutorial Group Effectivenes Instrument (TGEI), Intrinsic Motivation Inventory (IMI), dan 20 soal pilihan berganda. Beda rerata dinilai dengan "Cohen's $d$ " dengan kemaknaan praktis nilai Cohen's $d>1$.

Pemilihan rancangan penelitian ini dapat mengendalikan sebagian besar ancaman terhadap validitas internal penelitian. Differential attrition dikendalikan dengan pemilihan waktu penelitian yang 
tidak terlalu panjang. Validitas internal yang kuat pada penelitian ini mempengaruhi generalisasi hasil penelitian ini pada populasi yang lebih luas.

\section{HASIL DAN PEMBAHASAN}

Tidak terdapat perbedaan yang bermakna secara praktis antara kelompok perlakuan dan kelompok kontrol pada keseluruhan dimensi dari kuesioner TGEI (Tabel 1). Perbedaan rerata (SD) berbagai dimensi TGEI antara kelompok perlakuan dan kelompok kontrol berturutturut adalah: dimensi kognitif $(4.20 \pm 0.37$ vs $4.08 \pm$ 0.37 , Cohen's $d=0.32$ ), dimensi motivasi $(4.22 \pm 0.29$ vs $4.25 \pm 0.46$, Cohen's $d=-0.08)$, dimensi demotivasi $(3.18$ \pm 0.77 vs $2.65 \pm 0.50$, Cohen's $d=0.83)$ dan performa diskusi kelompok ( $4.28 \pm 0.57$ vs $4.18 \pm 0.73$, Cohen's $d=0.15$ ). Tidak terdapat perbedaan secara praktis antara kelompok perlakuan dan kelompok kontrol untuk keseluruhan nilai kuesionar TGEI (3.84 \pm 0.19 vs 3.94 0.28 , Cohen's $d=-0.41)$. Tanda negatif $(-)$ pada Cohen's $d$ menandakan nilai rerata kelompok kontrol lebih tinggi dibandingkan dengan kelompok perlakuan dan sebaliknya.

Tidak terdapat perbedaan yang bermakna secara praktis berbagai dimensi kuesioner IMI antara kelompok perlakuan dan kelompok kontrol (Tabel 2). Perbedaan rerata $(S D)$ berbagai dimensi IMI antara kelompok perlakuan dan kelompok kontrol berturut-turut adalah: dimensi kesenangan $(5.68 \pm 0.74$ vs $6.04 \pm 0.77$, Cohen's $d=-0.48)$, dimensi usaha (5.03 \pm 0.69 vs $5.62 \pm 0.71$, Cohen's $d=-0.84)$, dimensi nilai (5.98 \pm 0.86 vs $6.49 \pm$ 0.68 , Cohen's $d=-0.67)$, dimensi ketegangan (3.05 \pm 0.74 vs $2.49 \pm 0.88$, Cohen's $d=0.68$ ). Tidak terdapat perbedaan secara praktis antara kelompok perlakuan dan kelompok kontrol untuk keseluruhan nilai kuesionar $\operatorname{IMI}(5.41 \pm 0.57$ vs $5.91 \pm 0.63$, Cohen's $d=-0.83)$. Tanda negatif $(-)$ pada Cohen's $d$ menandakan nilai rerata kelompok kontrol lebih tinggi dibandingkan dengan kelompok perlakuan dan sebaliknya.

Tabel 1. Perbandingan rerata masing-masing dimensi dari TGEI antara kelompok perlakuan dan kelompok kontrol (skala likert 1 - 5)

\begin{tabular}{lccc}
\multirow{2}{*}{ Dimensi } & \multicolumn{2}{c}{ Kelompok } & \multirow{2}{*}{ Cohen's $d$} \\
\cline { 2 - 3 } & Perlakuan & Kontrol & \\
Kognitif & & & \\
$\quad$ Rerata & 4.20 & 4.08 & 0.32 \\
SD & 0.37 & 0.37 & \\
Motivasi & & & \\
$\quad$ Rerata & 4.22 & 4.25 & -0.08 \\
$\quad$ SD & 0.29 & 0.46 & \\
Demotivasi & & & \\
$\quad$ Rerata & 3.18 & 2.65 & 0.83 \\
$\quad$ SD & 0.77 & 0.50 & \\
Performa diskusi & & & \\
$\quad$ Rerata & 4.28 & 4.18 & 0.15 \\
$\quad$ SD & 0.57 & 0.73 & \\
Total nilai TGEI & & & \\
$\quad$ Rerata & 3.84 & 3.94 & -0.41 \\
$\quad$ SD & 0.19 & 0.28 & \\
\hline
\end{tabular}


Tabel 2. Perbandingan rerata masing-masing dimensi dari IMI antara kelompok perlakuan dan kelompok kontrol (skala likert 1 - 7)

\begin{tabular}{lccc}
\multirow{2}{*}{ Dimensi } & \multicolumn{2}{c}{ Kelompok } & \multirow{2}{*}{ Cohen's d } \\
\cline { 2 - 3 } & Perlakuan & Kontrol & \\
Kesenangan & & & \\
$\quad$ Rerata & 5.68 & 6.04 & \multirow{2}{*}{0.48} \\
SD & 0.74 & 0.77 & \\
Usaha & & & \\
$\quad$ Rerata & 5.03 & 5.62 & \multirow{2}{*}{0.84} \\
$\quad$ SD & 0.69 & 0.71 & \\
Nilai & & & \\
$\quad$ Rerata & 5.98 & 6.49 & \multirow{2}{*}{0.67} \\
$\quad$ SD & 0.86 & 0.68 & \\
Ketegangan & & & \\
$\quad$ Rerata & 3.05 & 2.49 & 0.68 \\
$\quad$ SD & 0.74 & 0.88 & \\
Total Nilai IMI & & & \multirow{2}{*}{0.83} \\
$\quad$ Rerata & 5.41 & 0.57 & \\
SD & 5.91 & 0.63 & \\
\hline
\end{tabular}

Data di atas menunjukkan rerata nilai modul pada mahasiswa yang berperan sebagai tutor sebaya lebih tinggi dibandingkan dengan mahasiswa yang berperan sebagai peserta diskusi biasa dengan perbandingan nilai rerata $11.66 \pm 0.51$ us $10.72 \pm 0.50$ dengan nilai Cohen's $d$ 1.86. Ini menunjukkan pengaruh yang kuat dan bermakna secara praktis antara peran mengajar dan peserta diskusi terhadap rerata nilai modul.

Hasil penelitian ini menunjukkan tidak ada perbedaan yang bermakna secara praktis antara efektivitas diskusi kelompok dan motivasi intrinsik antara yang difasilitasi oleh tutor sebaya dengan diskusi kelompok yang difasilitasi tutor dosen. Hasil penelitian pada aspek efektivitas diskusi kelompok ini sesuai dengan penelitian sebelumnya. ${ }^{18}$ Nilai modul pada mahasiswa yang difasilitasi oleh tutor sebaya lebih tinggi dibandingkan dengan mahasiswa yang difasilitasi oleh tutor dosen dan perbedaan ini bermakna secara praktis. Hasil penelitian pada aspek nilai modul ini tidak sesuai dengan banyak penelitian tentang penerapan tutor sebaya dalam pembelajaran berbasis masalah, yang menemukan bahwa diskusi kelompok yang difasilitasi oleh mahasiswa sama efektifnya dalam pencapaian tujuan belajar dibandingkan dengan diskusi kelompok yang difasilitasi oleh dosen. ${ }^{18,19,20}$
Keberhasilan diskusi kelompok salah satunya dipengaruhi oleh perilaku tutor. Perbedaan antara tutor sebaya dan tutor dosen terletak pada perilaku tutor, yang terdiri dari keselarasan peran, keselarasan kognitif dan penguasaan materi yang berhubungan dengan pencapaian mahasiswa. Konsep tersebut sesuai dengan teori keselarasan kognitif (cognitive congruence). ${ }^{21}$ Keselarasan kognitif merupakan kondisi yang diperlukan agar tutor dapat berfungsi dengan efektif. Jika tutor tidak mampu membingkai penjelasan yang diberikan kepada mahasiswa dalam bahasa yang dapat dipahami oleh mahasiswa, maka penjelasan yang diberikan akan lewat begitu saja tanpa diperhatikan oleh mahasiswa. Keselarasan kognitif juga diasumsikan sebagai kepekaan dari tutor mengenai kesulitan-kesulitan yang mungkin dihadapi oleh mahasiswa ketika bertemu dengan permasalahan atau materi yang terkait dengan permasalahan yang dibahas. Tutor akan mengetahui kapan harus melakukan intervensi dan apa yang dilakukan: bertanya untuk melakukan klarifikasi, memberikan contoh perbandingan, atau memberikan penjelasan singkat kepada mahasiswa. Tutor hanya dapat melakukan ini dengan baik jika mempunyai penguasaan materi yang relevan dan mempunyai perhatian terhadap kehidupan mahasiswa dan proses belajarnya. Tanpa penguasaan materi, tutor akan sulit mengikuti garis 
pemahaman mahasiswa dan tanpa mempunyai perhatian terhadap mahasiswa dan proses belajarnya tutor tidak akan mempunyai dorongan untuk memahami kesulitan yang dihadapi mahasiswa dalam pembelajarannya. Oleh karena itu, baik penguasaan materi dan kualitas interpersonal dari tutor diperlukan untuk timbulnya keselarasan kognitif.

Hasil analisis perilaku tutor antara tutor sebaya dan tutor dosen menunjukkan tidak terdapat perbedaan bermakna pada keselarasan peran dan penguasaan materi antara tutor sebaya dan tutor dosen. Perbedaan tidak bermakna pada efektivitas diskusi kelompok dan motivasi intrinsik pada mahasiswa yang difasilitasi tutor sebaya dan tutor dosen mungkin disebabkan karena tidak berbedanya tingkat keselarasan peran dan penguasaan materi antara tutor sebaya dan tutor dosen.

Terdapat perbedaan yang bermakna secara praktis antara kelompok perlakuan dan kelompok kontrol untuk variabel nilai modul $(10.72 \pm 0.50$ vs $9.27 \pm 0.48$, Cohen's $d=2.96)$ seperti yang ditunjukkan dalam Tabel 3. Perbandingan nilai rerata nilai modul pada kelompok perlakuan antara mahasiswa yang bertindak sebagai peserta diskusi dibandingkan dengan yang berperan sebagai tutor sebaya ditunjukkan oleh tabel 4 .
Nilai rerata modul pada mahasiswa yang difisilitasi tutor sebaya ternyata lebih tinggi secara bermakna dibandingkan dengan mahasiswa yang difasilitasi tutor dosen. Hal ini tidak sesuai dengan teori konseptual yang menyatakan pencapaian nilai mahasiswa akan dipengaruhi efektivitas diskusi kelompok. ${ }^{21}$ Faktor lain yang perlu dipertimbangkan dalam penelitian ini adalah adanya pengaruh kompensasi dari mahasiswa yang difasilitasi oleh tutor sebaya. Mahasiswa dapat menganggap tutor sebaya kurang kompeten sebagai fasilitator sehingga mereka termotivasi untuk mengkompensasi kekurangan tersebut dengan belajar lebih giat. Hasil belajar tersebut tidak terlihat dalam efektivitas diskusi kelompok dan motivasi intrinsik, karena keduanya sangat dipengaruhi oleh perilaku tutor. Hasilnya terlihat dalam nilai modul. Mungkin ini merupakan salah satu penyebab mengapa nilai modul mahasiswa yang difasilitasi oleh tutor sebaya lebih tinggi secara bermakna dibandingkan dengan nilai modul mahasiswa yang difasilitasi tutor dosen.

Nilai rerata modul antara mahasiswa yang berperan sebagai tutor sebaya ternyata lebih tinggi secara bermakna dibandingkan dengan mahasiswa yang hanya berperan sebagai peserta diskusi. Hasil penelitian ini juga konsisten dengan hasil penelitian lainnya dalam

Tabel 3. Perbandingan rerata nilai modul antara kelompok perlakuan dan kelompok kontrol (rentang nilai 0 - 20)

\begin{tabular}{lccc}
\multirow{2}{*}{ Subjek } & \multicolumn{2}{c}{ Nilai modul } & \multirow{2}{*}{ Cohen's $d$} \\
\cline { 2 - 3 } & rerata & SD & \\
Kelompok perlakuan & 10.72 & 0.50 & 2.96 \\
Kelompok kontrol & 9.27 & 0.48 & \\
\hline
\end{tabular}

Tabel 4. Perbandingan rerata nilai modul antara tutor sebaya dan peserta diskusi (rentang nilai 0 - 20)

\begin{tabular}{llcc} 
Subjek kelompok & \multicolumn{2}{c}{ Nilai modul } & \\
\cline { 2 - 3 } \multicolumn{1}{c}{ perlakuan } & rerata & SD & \\
Tutor sebaya & 11.66 & 0.51 & 1.86 \\
Peserta diskusi & 10.72 & 0.50 & \\
\hline
\end{tabular}


literatur psikologi dan pendidikan kedokteran yang menunjukkan sebuah keuntungan pembelajaran yang terkait dengan keterlibatan mahasiswa dalam mengajar. ${ }^{17,22,23,24}$ Hasil ini dapat mengkonfirmasi bahwa peran sebagai tutor sebaya dapat berpengaruh positif bagi mahasiswa.

Alasan yang paling masuk akal dari manfaat mempersiapkan diri untuk mengajar adalah lebih banyak waktu yang dihabiskan dalam belajar akan membuat ingatan terhadap apa yang dipelajari lebih baik. Dalam penelitian sebelumnya, ternyata waktu persiapan yang sama akan menimbulkan pencapaian tujuan belajar yang berbeda. ${ }^{14} \mathrm{Hal}$ ini menyebabkan waktu persiapan bukanlah satu-satunya faktor yang membedakan tutor sebaya dengan peserta diskusi. Mempersiapkan diri untuk mengajar menimbulkan tekanan yang lebih besar dibandingkan mempersiapkan diri sebagai peserta diskusi kelompok. Tutor sebaya dalam penelitian ini mungkin lebih sadar terhadap proses belajarnya-metakognisi, ${ }^{25}$ menghabiskan lebih banyak waktu dalam mengorganisasi pengetahuannya, ${ }^{14}$ meningkatkan kedalaman dan keluasan dari membaca materi, ${ }^{26}$ dan pengulangan secara verbal. ${ }^{27}$

Beberapa kelemahan dalam penelitian ini, antara lain durasi penelitian yang relatif pendek dan penggunaan soal pilihan berganda yang untuk menilai capaian belajar mahasiswa. Beberapa saran yang bisa diberikan untuk penelitian selanjutnya adalah: 1) waktu penelitian diperpanjang, sehingga dapat dilihat efek jangka panjang dari penerapan diskusi kelompok yang difasilitasi oleh tutor sebaya dibandingkan dengan dosen; 2) untuk menilai capaian kognitif, selain soal pilihan berganda sebaiknya digunakan juga soal-soal yang mampu menilai fungsi kognitif yang lebih tinggi misalnya menggunakan esai atau script concordance test; 3) perlu dipertimbangkan untuk membuat variasi dari tingkatan tutor dosen yang dibandingkan, misalnya tutor pemula dan tutor ahli; 4) perlu dilakukan triangulasi instrumen penilaian dalam menilai diskusi kelompok, misalnya dengan observasi langsung maupun rekaman.

\section{KESIMPULAN}

Terakhir, penelitian ini menyimpulkan tutor sebaya dapat memfasilitasi diskusi kelompok sama baiknya dengan tutor dosen pada parameter keefektifan diskusi kelompok, motivasi intrinsik dan nilai modul. Terdapat keuntungan bagi mahasiswa yang diberikan peran sebagai tutor sebaya.

\section{DAFTAR PUSTAKA}

1. Neville, A.J. The problem-based learning tutor: Teacher? Facilitator? Evaluator? Medical Teacher. 1999;21(4):393-401.

2. Bulte, C., Betts, A., Garner, K., \& Durning, S. Student teaching: view of student near-peer teachers and learners. Medical Teacher. 2007;29:583-90.

3. Dandavino, M., Snell, L., \& Wiseman, J. Why medical students should learn how to teach. Medical Teacher. 2007;29:558-65.

4. Ross, M.T., \& Cumming, A.D. Peer - assisted learning. Dalam: Harden, R.M., \& Dent, J.A. A practical guide for medical teacher. New York: Churcill Livingstone Elsevier; 2009.

5. Ten Cate, O., \& Durning, S. Peer teaching in medical education: twelve reasons to move from theory to practice. Medical Teacher. 2007;29(1):591-9.

6. Ten Cate, O., \& Durning, S. Dimensions and psychology of peer teaching in medical education. Medical Teacher. 2007;29(2):546-52.

7. Benware, C.A., \& Deci, E.L. Quality of learning with an active versus passive motivational set. American Educational Research Journal. 1984;21(4):755-65.

8. Deci, E.D., \& Ryan, R.M. Self-determination theory: A macrotheory of human motivation, development, and health. Canadian Psychology. 2008;49(3):1825.

9. Tolsgaard, M.G., Gustafsson, A., Rasmusen, M.B., Hoiby, C., Muller, C.G. \& Ringsted, C. Students teachers can be as good as associate professors in teaching clinical skills. Medical Teacher. 2007;29:5537.

10. Field, M., Burke, J., Lloyd, D. \& McAllister, D. Peerassisted learning in clinical examination. Lancet. 2004;363:490-1.

11. Weyrich, P., Celebi, N., Schrauth, M., Moltner, A., Lammerding-Koppel, M. \& Nikendei, C. Peer-assisted versus faculty staff-led skills laboratory training: a randomized controlled trial. Medical Education. 2009;43:113-20.

12. Unver, V., Akbayrak, N., \& Tosun, N. Efficiency of the peer tutoring model in skills training. HealthMED. 2011;5(5):1091-9.

13. Ten Cate, O., Van de Forst, I., Van den Broek, S. Academic achievement of students tutored by nearpeers. International Journal of Medical Education. 2012;3:6-13. 
14. Gregory, A., Walker, I., Mclaughlin, K., \& Peets, A.D. Both preparing to teach and teaching positively impact learning outcomes for peer teachers. Medical Teacher. 2011;33:427-32.

15. Sobral, D.T. Cross year tutoring experience in medical school: condition and outcomes for student tutors. Medical Education. 2002;36:1064-70.

16. Lockspeiser, T.M., O’Sullivan, P., Teherani, A., \& Muller, J. Understanding the experience of being taught by peers: the value of social and cognitive congruence. Advance in Health Science Education. 2008;13:361-72.

17. Peets, A.D., Coderre, S., Wright, B., Jenkins, D., Burak, K., Leskosky, S., \& McLaughlin, K. Involvement in teaching improves learning in medical students: a randomized cross-over study. BMC Medical Education [Internet]. 2009;9(55) Accessed 30 January 2012 from: http://www.biomedcentral. com/1472-6920/8/18

18. Kassab, S., Abu-Hijleh, M.F., Al-Shboul, Q., \& Hamdy, H. Student-led tutorials in problem-based learning: educational outcomes and students' perceptions. Medical Teacher. 2005;27(6):521-6.

19. Steele, D.J., Medder, J.D., \& Turner P. A comparison of learning outcomes and attitudes in student-versus faculty-led problem-based learning: an experimental study. Medical Education. 2000;34(1):23-9.

20. Sobral, D.T. Peer tutoring and student outcomes in a problem-based course. Medical Education. 1994; 28(4):284-9.
21. Schmidt, H.G., \& Moust, J.H.C. What makes a tutor effective? A structural-equations modeling approach to learning in problem-based learning curricula. Academic Medicine. 1995;70(8):708-14.

22. Cohen, P., Kulik, J., \& Kulik, C. Educational outcomes of tutoring: a meta-analysis of findings. American Educational Research Journal. 1982;19:237-48.

23. Tang, T., Hernandez., \& Adams, B. "Learning by teaching": A peer-teaching model for diversity training in medical school. Teach Learn Med. 2004;16:60-3.

24. Wong, J., Waldrep, T.\& Smith, T. Formal peerteaching in medical school improves academic performance: The MUSC supplemental instructor program. Teach Learn Med. 2007;19:216-20.

25. Prins, F.J., Veenman, M.V.J., \& Elshout, J.J. The impact of intellectual ability and metacognition on learning: New Support for the threshold of problematicity theory. Learn Instruct. 2006;16:37487.

26. Chamorro-Premuzic, T. \& Furnham, A. Personality, intelligence, and approaches to learning as predictor of academic performance. Pers Individ Dif. 2008;44:1596-603.

27. Dawson, M.D. The effect of reinforcement and verbal rehearsal on selective attention in learning-disabled children. J Abnormal Child Psychol. 1980;8:133-44. 